\title{
Combined Transapical Transcatheter Aortic Valve Replacement and Thoracic Endovascular Aortic Repair for Severe Aortic Stenosis and Arch Aneurysm
}

\author{
Yuanjia Zhu, BS 1 , Eric E. Roselli, MD ${ }^{1,2^{*}}$, Jay J. Idrees, MD ${ }^{1,2}$, Samir Kapadia, MD, \\ Lars G. Svensson, MD, PhD ${ }^{1,2}$ \\ ${ }^{1}$ Aortic Center, Heart and Vascular Institute, Cleveland Clinic, Cleveland, Ohio, USA \\ ${ }^{2}$ Department of Thoracic and Cardiovascular Surgery, Heart and Vascular Institute, Cleveland Clinic, Cleveland, Ohio, USA \\ ${ }^{3}$ Department of Cardiovascular Medicine, Heart and Vascular Institute, Cleveland Clinic, Cleveland, Ohio, USA
}

\begin{abstract}
An 83-year-old male with multiple comorbidities presented with critical aortic stenosis and a saccular aortic arch aneurysm. Through a mini thoracotomy, a balloon expandable transcatheter aortic valve was delivered transapically. A thoracic stent graft was then delivered through the prosthetic valve and deployed in the arch, while a covered stent was deployed in the left common carotid artery. Three-year postoperative computed tomography showed a thrombosed arch aneurysm with decreased size. This case demonstrates the feasibility of using combined transapical transcatheter technologies to treat multicomponent disease in a high-risk patient during a single operation.

Copyright $\odot 2016$ Science International Corp.
\end{abstract}

\section{Key Words}

Aortic valve - Aortic arch aneurysm - Thoracic endovascular aortic repair.

\section{Introduction}

Transcatheter approaches for managing complex aortic and aortic valve disease have been rapidly adopted, especially for high-risk patients. Increasing

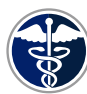

Fax +1 2037853552

E-Mail:aorta@scienceinternational.org

http://aorta.scienceinternational.org

\author{
(c) 2016 AORTA \\ Published by Science International Corp. \\ ISSN 2325-4637 \\ Accessible online at: \\ http://aorta.scienceinternational.org
}

understanding of valve disease and technological advancements continue to improve outcomes [1, 2]. A significant proportion of patients with aortic stenosis (AS) also have thoracic aortic aneurysm that warrants intervention. In high-risk patients, treating both lesions simultaneously may compound the risk for surgical repair. In this case report, combined transapical transcatheter aortic valve replacement (TAVR) and thoracic endovascular aortic repair (TEVAR) were performed successfully to treat critical AS and aortic arch aneurysm during a single operation.

\section{Case Presentation}

An 83-year-old male presented with dyspnea on exertion in concert with New York Heart Association Class III symptoms secondary to known severe AS. The patient's past medical history included hypertension, hyperlipidemia, chronic obstructive pulmonary disease, insulin-dependent diabetes, cerebrovascular accident, and lung cancer postradiation. He also had a history of coronary artery disease and ascending aortic aneurysm. The patient underwent triple coronary artery bypass grafting in 1979 and again in 1996

* Corresponding Author:

Eric E. Roselli, MD

Department of Thoracic and Cardiovascular Surgery Cleveland Clinic

9500 Euclid Avenue, Desk J4-1, Cleveland, OH, USA

Tel.: +1 216444 0995, Fax: +1 216636 1393, E-Mail: roselle@ccf.org 
for this condition, including ascending aortic replacement with an interposition polyester graft.

A preoperative echocardiogram showed a left ventricular ejection fraction of $53 \%$ with moderate aortic valve regurgitation and severe AS. Mean and peak gradients were 40 and $67 \mathrm{~mm} \mathrm{Hg}$, respectively, with an area of $0.74 \mathrm{~cm}^{2}$. Preoperative computed tomography angiography (CTA) revealed an aortic arch saccular aneurysm that measured $4.2 \mathrm{~cm}$ in diameter and abutted the left subclavian artery (Figure 1). Iliac arteries were severely tortuous with calcified atherosclerotic changes. Cardiac catheterization showed patent coronary artery bypass grafts. The patient was deemed very high risk for both open cardiac surgery and transfemoral approaches. Thus, we recommended transapical endovascular repair with arch TEVAR and TAVR.

One day before the endovascular repairs, the patient underwent left common carotid artery-toleft subclavian artery bypass with an 8-mm ringed polytetrafluoroethylene interposition graft. Via a mini thoracotomy, concentric purse-string sutures were placed in the left ventricular apex, followed by wire ac- cess across the aortic valve. Access into the ascending aorta was obtained through the left common carotid artery. Percutaneous femoral access was used for angiography. Balloon valvuloplasty was performed, and then an Edwards Sapien 26-mm prosthetic valve was deployed during rapid ventricular pacing. Using the same wire through the transapical sheath, a $32 \mathrm{~mm}$ $\times 120 \mathrm{~mm}$ Zenith TX2 stent graft (Cook Inc., Bloomington, IN, USA) was delivered through the prosthetic valve across the aortic arch with the back end of the device aligned with the innominate artery. Because an adequate landing zone required partial coverage of the left common carotid artery, a $10 \mathrm{~mm} \times 5 \mathrm{~cm}$ Viabahn endovascular stent graft (Gore, Flagstaff, AZ, USA) was inserted into the left common carotid artery. The arch stent graft was then deployed during rapid ventricular pacing followed by the left common carotid stent graft. Both stent grafts were expanded via the balloons to optimize conformability. The postoperative echocardiogram confirmed a well-seated prosthetic valve with $1+$ posterior paravalvular leak. CTA demonstrated an excellent aortic repair with patent arch branch vessels and no endoleak. One month

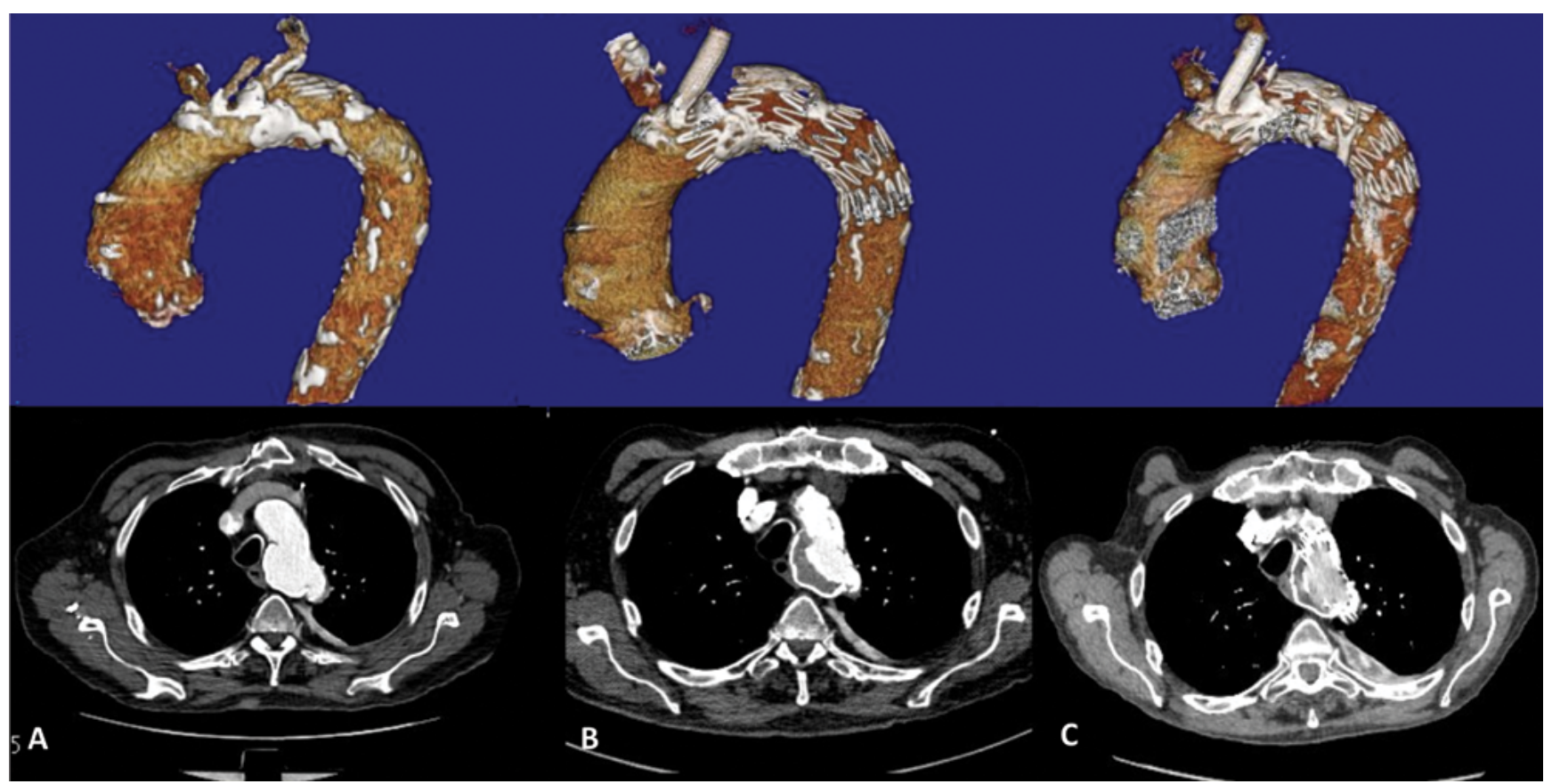

Figure 1. Pre- and postoperative computed tomography $(C T)$ images with volume-rendered reconstruction $C T$ and a transverse view of the aneurysm. Panel A. Preoperative CT showing an aortic arch aneurysm that abuts the left subclavian artery. Panel B. Postoperative CT image showing excellent aneurysm repair and aortic valve implantation. Panel C. CT image taken 3 years postprocedure shows a thrombosed arch aneurysm with decreased size. 
postoperatively, the echocardiogram and CTA findings remained unchanged (Figure 1). The patient was still alive and asymptomatic 3 years postoperatively. The CTA at follow-up exhibited a thrombosed arch aneurysm that measured $3.9 \mathrm{~cm}$ in diameter (Figure 1).

\section{Discussion}

This case demonstrates the feasibility of combining two different transcatheter technologies to treat multicomponent disease in a high-risk patient via the transapical route in a single operation. Aortic valve disease is commonly associated with thoracic aortic aneurysm. As a result, as we continue to offer TAVR to more high-risk patients, it is likely that we will see more patients with combined valve and aortic disease $[3,4]$. The transapical approach has evolved in recent years and is associated with minimal mortality when performed by experienced surgical teams [5]. With the use of three different commercially available devices, we were able to design a treatment strategy to fit the patient's anatomy [6]. As we expand en- dovascular therapies to the proximal aorta, we will require disease-specific devices, such as those with branches for the arch vessels [7]. Further development of transcatheter technology will likely include the combination of TAVR and TEVAR as a treatment option in patients with even more proximal thoracic aortic disease that encroach on or involve the aortic root [8].

\section{Acknowledgements}

Dr Roselli receives honoraria for training from Cook.

\section{Conflict of Interest}

The authors have no conflict of interest relevant to this publication.

\section{Comment on this Article or Ask a Question}

\section{References}

1. Mack MJ, Leon MB, Smith CR, Miller DC, Moses JW, Tuzcu EM, et al. 5-year outcomes of transcatheter aortic valve replacement or surgical aortic valve replacement for high surgical risk patients with aortic stenosis (PARTNER 1): a randomised controlled trial. Lancet. 2015;385:2477-2484. DOI: 10.1016/ S0140-6736(15)60308-7.

2. Roselli EE, Idrees J, Greenberg RK, Johnston DR, Lytle BW. Endovascular stent grafting for ascending aorta repair in high-risk patients. J Thorac Cardiovasc Surg. 2015;149:144-154. DOI: 10.1016/ j. jtcvs.2014.07.109.

3. Komlo CMM, Vallabhajosyula $\mathrm{P}$, Bavaria JE, Desai ND, Anwaruddin S, Giri JS, et al. Combined transaortic transcatheter valve replacement and thoracic endografting. Ann Thorac Surg. 2014;97:696-698. DOI: 10.1016/j.athoracsur.2013.05.099.

4. Allen KB, Davis JR, Cohen DJ. Critical aortic stenosis and acute ascending aortic penetrating ulcer managed utilizing transapical TAVR and TEVAR. Catheter Cardiovasc Interv. 2015;86:768-772. DOI: 10.1002/ ccd. 25816

5. Aguirre J, Waskowski R, Poddar K, Kapadia $S$, Krishnaswamy A, McCullough R, et al. Transcatheter aortic valve replacement: Experience with the transapical approach, alternate access sites, and concomitant cardiac repairs. J Thorac Cardiovasc Surg. 2014;148:1417-1422. DOI: 10.1016/j. jtcvs.2014.05.019.

6. Ohrlander T, Sonesson B, Ivancev K, Resch T, Dias N, Malina M. The chimney graft: a technique for preserving or rescuing aortic branch vessels in stent-graft sealing zones. J Endovasc Ther. 2008;15:427-432. DOI: 10.1583/07-2315.1.

7. Roselli EE, Arko FR, Thompson MM, Valiant Mona LSA. Trial Investigators. Results of the Valiant Mona LSA early feasibility study for descending thoracic aneurysms. J Vasc Surg. 2015;62:1465-1471. DOI: 10.1016/j. jvs.2015.07.078.

8. Rylski B, Szeto WY, Bavaria JE, Branchetti E, Moser W, Milewski RK. Development of a single endovascular device for aortic valve replacement and ascending aortic repair. J Card Surg. 2014;29:371-376. DOI: 10.1111/ jocs.12348.

Cite this article as: Zhu Y, Roselli EE, Idrees JJ, Kapadia S, Svensson LG. Combined Transapical Transcatheter Aortic Valve Replacement and Thoracic Endovascular Aortic Repair for Severe Aortic Stenosis and Arch Aneurysm. AORTA (Stamford). 2016;4(5):175-177. DOI: $\quad$ http://dx.doi.org/10.12945/j. aorta.2016.16.030 